\title{
ANALYSIS OF SOCCER LEAGUE COMPETITION ALGORITHM FOR LOAD FREQUENCY CONTROL IN NONLINEAR INTERCONNECTED POWER SYSTEM
}

\author{
Ahmet DOĞAN* \\ Nuh Naci Yazgan University, Engineering Faculty, Department of Electrical-Electronics Engineering, Kayseri, \\ Turkey
}

\begin{tabular}{ll}
\hline Keywords & Abstract \\
\hline Optimization, & Load Frequency Control (LFC) is a significant tool that provides an equilibrium \\
PID, & between generated and consumed real power for efficient operation of power \\
Heuristic Algorithms. & system. In this paper, design and performance analysis of Soccer League \\
& Competition (SLC) algorithm is provided for optimal solution of LFC in nonlinear \\
& interconnected power systems. SLC algorithm has ability of escaping from local \\
& minimum while increasing searching capability accuracy with their operators. SLC \\
& is employed for 50, 100 and 200 iteration numbers to decide PID controller \\
parameters for minimizing Integral of Time multiplied Absolute Error (ITAE) as \\
objective function. In order to demonstrate efficiency of SLC, two different nonlinear \\
test systems are employed as case studies. At the first instant of study, two area \\
nonlinear thermal power plants with proper value of Generation Rate Constraints is \\
considered as test system. Then, the simulations are employed for three-area \\
unequal power system consist of important system limitations such as generation \\
rate constraints, time delay and governor dead band. Performance of SLC is \\
compared to different heuristic algorithms such as Bacterial Foraging Optimization \\
Algorithm (BFOA), hybrid Firefly Algorithm and Pattern Search (hFA-PS), Particle \\
Swarm Optimization (PSO) and Artificial Bee Colony (ABC). Simulation results \\
reveal that better dynamic performances of different test systems are obtained \\
using SLC among the considered algorithms.
\end{tabular}

\section{FUTBOL LİGi MÜSABAKASI ALGORITMASININ DOĞRUSAL OLMAYAN VE BİRBİRINNE BAĞLI GÜÇ SİSTEMLERİNDE YÜK FREKANS KONTROLÜ İÇİN ANALİZi}

\begin{tabular}{|c|c|}
\hline Anahtar Kelimeler & Öz \\
\hline $\begin{array}{l}\text { Yük Frekans Kontrolü, } \\
\text { Optimizasyon, } \\
\text { PID, } \\
\text { Sezgisel Algoritmalar. }\end{array}$ & $\begin{array}{l}\text { Yük Frekans Kontrolü (YFK), güç sistemlerinin verimli çalışması için üretilen ve } \\
\text { tüketilen aktif güç arasındaki dengeyi sağlayan önemli bir araçtır. Bu çalışmada, } \\
\text { doğrusal olmayan ve birbirine bağlı alanların bulunduğu güç sistemlerinde YFK'nın } \\
\text { optimum çözümü için Futbol Ligi Müsabakası (FLM) algoritmasının tasarım ve } \\
\text { performans analizi gerçekleştirilmiştir. FLM algoritması, operatörleri sayesinde } \\
\text { arama kabiliyetinin doğruluğunu artırırken yerel minimumlardan kaçabilmektedir. } \\
\text { FLM algoritması, zamanla çoğaltılmış mutlak hatanın integralini en aza indirmek } \\
\text { için PID denetleyicisinin parametre değerlerine karar vermek için kullanılmıştır. } \\
\text { FLM algoritmasının etkinliğinin göstermek için, benzetim çalışması olarak iki farklı } \\
\text { doğrusal olmayan test sisteminin benzetimi gerçekleştirilmiştir. İlk çalışmada, } \\
\text { uygun değerde üretim oranı kısıtlamaları olan iki bölgeli doğrusal olmayan termik } \\
\text { santral test sistemi göz önünde bulundurulmuştur. Daha sonra, üretim oranı } \\
\text { kısıtlamaları yanında governor etkisiz bölgesi ve zaman gecikmesi gibi önemli } \\
\text { fiziksel kısıtlamalardan oluşan eşit olmayan üç bölgeli güç sistemi üzerinde } \\
\text { araştırma yapılmıştır. Elde edilen sonuçlar, Bakteri Yiyecek Arama Optimizasyon, } \\
\text { hibrit Ateş Böceği-Örnek Arama, Yapay Arı Kolonisi ve Parçacık Sürü Optimizasyon } \\
\text { algoritmaları sonuçları ile karşılaştırılmıştır. Benzetim sonuçları, dikkate alınan } \\
\text { algoritmalar arasında FLM algoritması kullanılarak gerçekleştirilen benzetimlerde } \\
\text { test sistemlerinin daha iyi dinamik performans gösterdiğini ortaya koymaktadır. }\end{array}$ \\
\hline
\end{tabular}

\footnotetext{
* ilgili yazar / Corresponding author: adogan@nny.edu.tr
} 


\section{Alıntı / Cite}

Doğan, A., (2021). Analysis of Soccer League Competition Algorithm for Load Frequency Control of Nonlinear Interconnected Power System, Journal of Engineering Sciences and Design, 9(3), 866-879.

\begin{tabular}{l|l|l}
\hline Yazar Kimliği / Author ID (ORCID Number) & Makale Süreci / Article Process \\
\hline A. Doğan, 0000-0002-9552-1997 & Başvuru Tarihi / Submission Date & 28.11 .2020 \\
& Revizyon Tarihi / Revision Date & 28.05 .2021 \\
& Kabul Tarihi / Accepted Date & 16.06 .2021 \\
& Yayım Tarihi / Published Date & 21.09 .2021 \\
\hline
\end{tabular}

\section{Introduction}

Electrical power systems may involve numerous control areas with a variety of power sources that produce power to meet load demand. Besides, electricity companies have to supply uninterrupted, reliable, and efficient power to customers within acceptable quality due to importance of electrical power. The stable operation of interconnected power system is based on the equilibrium between load demand and generated power. Disparity between generation and consumption leads the distortion of the nominal frequency and output voltage. It can be said that the generation amount of the source is important in terms of stability and frequency deviation for power systems. Less power generation than power consumption causes a decrease in system frequency or vice versa. Namely, active power equilibrium is essential to keep the steady-state frequency error within acceptable values for proper operation of interconnected power systems. On the other hand, load frequency control (LFC) is defined as adjusting the active power output of the generation sources to keep deviations in system frequency and tie line power within the specified limits (Dogan, 2019). Today, LFC is becoming more important issue for power systems due to fast increase in number of integrated renewable and distributed energy sources which causes new physical constraints, complexity and uncertainties (Hasanien, 2018). Various classical control structures are used like Integral, Proportional-Integral and Proportional-Integral-Derivative (PID) to achieve control structure. PID controllers are generally preferred when fast response and stability is needed (Borase et al., 2020).

Another key point is that constant controller parameters cannot efficiently perform with respect to dynamic operating conditions and load variations. Thereby, it is necessary to be optimized gain coefficient of controllers based on load variation and system condition. Although fuzzy based methods are previously carried out to improve performance of stability, they require dataset, have complex operations and extensive computation times (Guha et al., 2018). Recently, heuristic optimization techniques are proposed for solving LFC problems due to their simplicity and they do not require dataset. In order to optimize controller parameters, some heuristic algorithms have been proposed in the literature. In (Guha et al., 2018), Backtracking Search Algorithm is employed to optimize PI/PID controller and it is compared to other algorithms in the literature. In (Guha et al., 2016), Grey Wolf Optimization is applied for different test systems. However, performances of the algorithms are not compared to any other algorithm for PID controller structure. In (Sahu et al., 2015a), a hybrid Firefly AlgorithmPattern Search (hFA-PS) technique is proposed to select PI and PID controllers' parameters at solution of LFC of interconnected power systems with their nonlinearities. Nevertheless, hybridization process requires more detailed classification. In (Guha et al., 2020), the whale optimization algorithm is individually applied to a two area thermal power plant and multi-source power plant with AC- DC tie-line. Time-delay, governor dead-band and generation rate constraint are also considered. Phase-locked loop, which increased the computational burden, is used for power system stability. In (Mahendran \& Vijayan, 2021), multi area and multi-source frequency controller is provided based on the dual-mode switch, which depends on threshold value. Combination of dragonfly algorithm and particle swarm optimization control algorithm optimized threshold of switch and PI controller parameters. In (Vedik et al., 2021) optimum frequency control of interconnected system is provided with various heuristic algorithms in presence of wind turbines and photovoltaic system. In (Wang et al., 2020), wind turbine fatigue load is considered for LFC problem. Two-areas LFC model including thermal power and hydropower models is created with fatigue load at low-speed shaft torque of the wind turbine. Differential evolution algorithm is employed for PID controller optimization. In (Hasanien, 2018), whale optimization algorithm is employed for optimally design the PID controllers in interconnected system including wind turbine, photovoltaic systems and wave energy sources. All the RES components are modelled under maximum power point tracking conditions. Integral square error (ISE) criterion is considered as objective function. In (Hasanien \& El-Fergany, 2019), salp swarm algorithm is used to decide the coefficients of PID controllers of LFC of a multi-area hybrid renewable nonlinear power system. Dead-band and generation rate constraint are implemented with the governor model and the turbine model, respectively. However, only two area power system is considered for investigation.

In the light of literature search, some system limitations such as time delay, generation rate constraints and generation dead band negatively affect the dynamic response of power system by increasing oscillation, settling time and overshoots (Hasanien \& El-Fergany, 2019). Linear approach of power system ignores real system constraints. Also, as the number of interconnected systems increase, frequency control becomes more difficult. In 
addition to all, the optimization algorithm is one of the most important factors in terms of frequency control performance. SLC can converge to global optimum by dividing players into fixed and substitution and using different operators (Moosavian \& Roodsari, 2014). Imitation and provocation operators are applied to fixed and substitute player of winner team, separately. The imitation operator enlarges the searching capability of the algorithm while the provocation operator increases the accuracy of the solutions in complex optimizations problems. The mutation and substitution operators provide escaping from local minimums. One of the most important features of SLC is that it can perform coarse and fine searches together. The fine scale search is employed between individual players while coarse scale search is performed between teams. In the fine scale, players of the each team try to enhance their performance to be the star player of the team and to be superstar player of the league, respectively. Other players moves to direction of the star player of each team which means try to reach better solution. Moreover, SLC conducts other teams to the optimum solution.

SLC algorithm has been successfully applied to different areas. In (Moosavian \& Kasaee Roodsari, 2014), SLC is employed for optimum design of water distribution networks. Best component size and settings are decided in order to obtain minimum cost. The results compared to algorithms such as PSO, GA, DE. The results indicates that SLC has cost value with lower number of function evaluations. In (Moosavian, 2015) , SLC is used to solve high dimensional knapsack problem. It provides better results than ABC and HS in terms of finding global optimums with high degree of reliability. In (Fujita et al., 2016), SLC has been applied to set covering problem to test the convergence capability. It has good convergence performance up to 2000 decision-variables and 200 constraints. In (Ebrahimi \& Tabatabaei, 2020), SLC is applied as optimization method for clustering sensor networks. It performs better than NODIC protocol. In (Qiao et al., 2020), deployment wireless sensor network problems are optimized using SLC and it provides better results in compare to firefly algorithm, genetic algorithm, and adaptive differential evolution are obtained. On the other side, a power system application of SLC is presented in (Dogan, 2021). Optimum sitting and sizing of renewable energy sources, energy storage system and electric vehicle charging station are provided for various power systems. Best value of objective function in repetitive simulation are better than grey wolf optimization algorithm. Although SLC is applied to various areas, there is not much application for power systems in the literature.

Considering all the abovementioned facts, contributions of the paper are expressed as follows;

- SLC algorithm, which have the ability of performing local and global research, is employed for the first time in order to optimize LFC. The obtained results of SLC are compared to other optimization as Bacterial Foraging Optimization Algorithm (BFOA), hybrid Firefly Algorithm and Pattern Search (hFA-PS), Particle Swarm Optimization (PSO) and Artificial Bee Colony (ABC).

- Interconnected power systems in presence of significant physical constraints and nonlinearities such as Time Delay (TD), Generation Rate Constraints (GRC) and dead band of governor (GDB) are taken account for examinations.

- Integrated time absolute error is considered as objective function. ITAE based adjusting makes the system to reach the steady state much faster than the other tuning methods. In addition, ITAE also minimizes peak overshoot.

- Firstly, Performance of the SLC algorithm is tested for two area multi source interconnected network and then unequal three area multi source interconnected power systems with nonlinearities is optimized for LFC problem.

The remaining part of this paper is organized as follows; Section 2 characterizes an explanation of LFC in interconnected power system and PID controller structure. Section 3 describe objective function and Section 4 explanations of SLC, PSO and ABC algorithms, respectively. Section 5 presents comparative analysis of SLC algorithm based on LFC in nonlinear power systems. Finally, conclusions are outlined in Section 6.

\section{Load Frequency Control and Controller Structure}

Load frequency control is required for keeping the frequency and tie line power variation in acceptable boundaries in normal operation and small disturbances, as well. Mathematical model of single area linear model is presented for LFC in Figure 1. Single area of interconnected system includes governor, speed governing system, turbine, generator and load (Sahu et al., 2015b). 


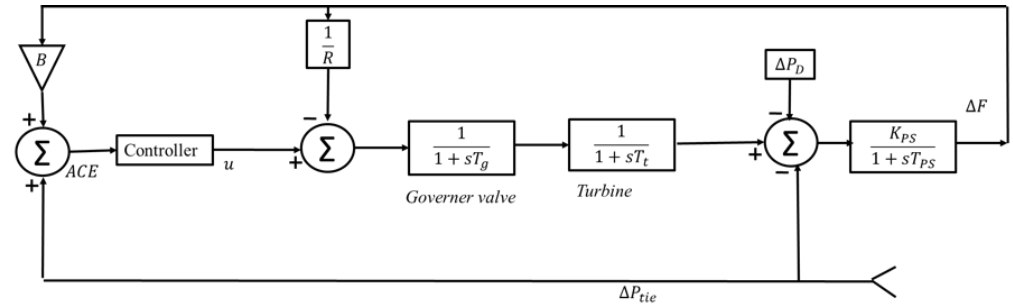

Figure 1. Single-area of interconnected power system.

Area Control Error $(A C E)$ which represents the active power imbalance between generation and consumption. The required $A C E$ in each area is used as reference for deciding controller parameters in order to approach $A C E$ to zero. The signal is employed to adjust the generator production as fast as possible based on the power system load demand when the interconnected areas are disturbed by any sudden load variation. ACE is defined for $n$th area as follows;

$$
A C E_{n}=B_{n} \Delta f_{n}-\Delta P_{\text {Tie }}
$$

where $B, \Delta f_{n}$ and $\Delta P_{T i e}$ are the frequency bias parameter, frequency deviation and tie line power change of the respective areas. Each components of the system are indicated by transfer functions for frequency domain analyses. Turbine transfer function is given by (2);

$$
G_{T}(s)=\frac{\Delta P_{T}(s)}{\Delta P_{V}(s)}=\frac{1}{1+s T_{T}}
$$

where $T_{T}$ is turbine time constant. Governor the transfer function is given by (3);

$$
G_{G}(s)=\frac{\Delta P_{V}(s)}{\Delta P_{G}(s)}=\frac{1}{1+s T_{G}}
$$

where $T_{G}$ is governor time constant. Reference power settings $\left(\Delta P_{r e f}(s)\right)$ and frequency deviations $(\Delta F(s))$ settle governor inputs and $\left(\Delta P_{G}(s)\right)$ indicates the governor output as follows;

$$
\Delta P_{G}(s)=\Delta P_{r e f}(s)-\frac{1}{R} \Delta f(s)
$$

where $R$ is speed regulation parameter. Generator and load transfer functions are given by (5);

$$
G_{P}(s)=\frac{K_{P}}{1+s T_{P}}
$$

Generator and load system has turbine power change $\left(\Delta P_{T}(s)\right)$, load disturbances $\left(\Delta P_{D}(s)\right)$ and tie line power changes $\left(\Delta P_{T i e}(s)\right)$ as input and frequency deviation $(\Delta f(s))$ as output.

$$
\Delta f(s)=G_{P}(s)\left[\Delta P_{T}(s)-\Delta P_{D}(s)\right]
$$

The turbine power changes depends on valve power variation $\left(\Delta P_{v}(s)\right)$ which depend on governer output signal $\left(\Delta P_{G}(s)\right)$. In normal steady state, turbine power and total power demands are on equilibrium with constant frequency.

LFC is provided using PID controller in this study. PID controllers are used in case of requirement of stability and fast response. Derivative controller increases performance of the power system and increases controller response speed. (7) represents the PID controller transfer function where $K_{p}, K_{i}$ and $K_{d}$ denote proportional, integral and 
derivative controller parameters, respectively.

$$
T F_{p i d}=K_{p}+K_{i}\left(\frac{1}{s}\right)+K_{d} s
$$

$u_{n}$ is outputs of the control area $\mathrm{n}$ as follows;

$$
u_{n}=A C E_{n}\left(K_{p, n}+\frac{K_{i, n}}{s}+K_{d, n} s\right)
$$

\section{Objective Function}

It is evident from previous studies that the efficient operation of the power system relies on the artificial intelligence method and controller structure in the meantime. Besides, objective function is also one of the important tools for LFC. Objective function is designed based on dynamic response that depends on desired system constraints and specifications. The considered essential qualifications are steady-state error, overshoot, settling time. Standard performance criteria are Integral of Time multiplied Absolute Error (ITAE), Integral of Squared Error (ISE), Integral of Absolute Error (IAE) and Integral of Time multiplied Squared Error (ITSE). It has been reported that ITAE tuning produces systems, which settle in a lesser time than the ISE tuning methods and ITAE is a most effective objective function in LFC studies (Sahu et al., 2015a). In a power system, it is desired that all output variables to be steady state and all fluctuations to be in specified limit as fast as possible. Long time later occurred errors are punished heavily than earlier occurred error of the response with multiplying error by the time applying ITAE criteria. Considered objective function is based on minimization of ITAE in order to increase dynamic performance of the system as below;

$$
J=I T A E=\int_{0}^{t s i m}\left(\sum_{n=1}^{n t o t}\left|\Delta f_{n}\right|+\sum_{m=1}^{m t o t}\left|\Delta P_{\text {tie, }, m}\right|\right) t . d t
$$

In the above equations, $\Delta f_{n}$ indicates frequency deviations of $n$th area. $\Delta P_{t i e, m}$ is the incremental change power of in $m$ th tie-line and tsim is the time range of simulation. $n$ defines number of area and ntot is total number of areas. Similarly, $m$ and mtot denote number of tie line and total number of tie lines, respectively. Measurement points of $\Delta f_{n}$ and $\Delta P_{t i e, m}$ are shown in the illustration of test system in Appendix. Objective function aims to settle down fast and minimize fluctuation in frequency deviation and tie line power. Hence disturbance of the overall system can be diminished.

\section{Definition of Algorithms}

\subsection{Soccer League Competition Algorithm}

Soccer League Competition (SLC) algorithm is proposed in 2014 (Moosavian \& Kasaee Roodsari, 2014;). In a soccer league, teams are in competition with each other to be the champion team at the end of the season. Each team has fixed player (FP) and reserve players (RP), as well. Match winning probability of teams increase proportional to performance of their players. Hence, all players try to achieve their best performance. Although the player performance is the main factor for victory, winner of the match cannot be known for certain before match played. Highest number of match winner team becomes champion at the end of the season.

Each players and teams effort to improve their performance for next match and every season. Power of player $(P P)$ defined as follows;

$$
\begin{aligned}
& P P(i, j)=1 / J(i, j), i \in \text { team }, j \in \text { player }, J=\text { objective function } \\
& i=1,2, \ldots, n \text { Teams }, j=1,2, \ldots,(n F P+n R P)
\end{aligned}
$$

$n$ Team denotes number of team in league, $n F P$ indicates number of fixed player in a team and $n R P$ denotes number of reserve player in a team. The total number of players in the league corresponds to number of solution vectors. The team power $(T P)$ is calculated as average of the power of the fixed players as follows; 


$$
T P(i)=(1 / n F P) \sum_{j=1}^{n F P} P P(i, j)
$$

The match winning probability for team $i$ in a match is given by;

$$
P v(i)=T P(i) /(T P(i)+T P(k))
$$

$P v(i)$ indicates winning probability of team $i$. It must be remembered that sum of winning probability of two teams must equal 1 . After each match, some players will be modified to improve the team performance for winner and loser team, as well. These changes are made through the so-called imitation and provocation operators for winner team, while substitution and mutation operators are provided for the loser team players. Flowchart of SLC is given as follows in Figure 2 (Dogan, 2021).

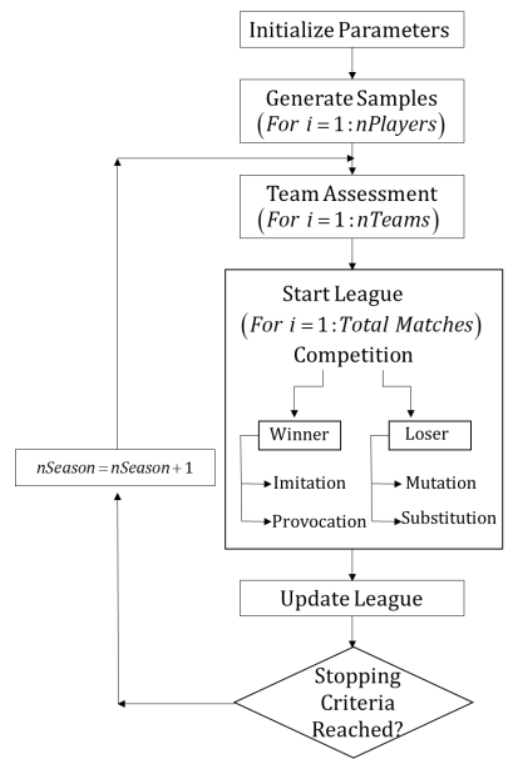

Figure 2. Flowchart of SLC

Each steps and operator of SLC algorithm are given as follows;

1. Samples generation: Initially, players and teams are randomly generated as given;

$$
\begin{aligned}
& x(i, j, k)=\operatorname{rand}\left[x^{\min }(i, j, k), x^{\max }(i, j, k)\right], \\
& i \in \text { team, } j \in \text { player }, k \in \text { variable }
\end{aligned}
$$

2. Teams assessment: If winning probability of $i$ th team is higher than random generated number, $i$ th team is winner of the match, otherwise it is loser team of the game.

$$
\begin{aligned}
& \text { team }_{i} \text { is winner, if } P v(i)>\operatorname{rand}[0,1] \\
& \text { team }_{k} \text { is winner, if } P v(i)<\operatorname{rand}[0,1]
\end{aligned}
$$

Each team makes revision by the operators to enhance their power. Winner team applies the imitation and provocation to $F P$ and $R P$, respectively. On the other side, Loser team applies the mutation and substitution operators to $F P$ and $R P$, respectively. Operators are formulated as follows;

a. Imitation: $F P$ of the winner team, try to be like $S P$ and $S S P$ by improving their player power in the league to reach to status of $S P$ and $S S P$. Namely, fixed player of winner team tries to be best in the team and in the league, as well. Imitation is performed for $i$ th team $j$ th fixed player by the following formulas;

$$
F P(i, j)=\mu_{1} F P(i, j)+\tau_{1}(S S P(i)-F P(i))+\tau_{1}(S P(i)-F P(i))
$$




$$
F P(i, j)=\mu_{2} F P(i, j)+\tau_{1}(\operatorname{SSP}(i)-F P(i))+\tau_{1}(\operatorname{SP}(i)-F P(i))
$$

First, the solution vectors of the winner team $F P$ perform a radical movement in the direction of the resulting vector of the $S S P$ as in (16). If generated vector is presents a better results, it is changed with old one. Else, solution vector performs a smaller movement as in (17). If this movement does not give a better result, the old vectors are preserved.

b. Provocation: Weakest reserve players of winner team try to reach team power in order to turn into $F P$ as follows;

$$
\begin{aligned}
& R(i, j)=T P(i)+\chi_{1} *(T P(i)-R(i, j)) \\
& R(i, j)=T P(i)+\chi_{2} *(R(i)-T P(i, j))
\end{aligned}
$$

First, the solution vectors of the weakest $R P$ in the winning team perform a forward movement in the direction of the gravity center of $F P$ as in (18). If generated vector is presents a better results, it is replaced with old one. Otherwise, weakest $R P$ in the winning team perform a backward movement in the direction of the gravity center of $F P$ as in (19). If the weakest reserve success to improve its performance, they are kept in the team. Else, it is replaced with a new random players.

c. Mutation: Position changes also should be applied on $F P$ of the loser team to improve player and team performances for next matches. This mechanism is similar mutation process of GA. Randomly selected decision variable of randomly selected $F P$ of loser team are replaced with mutation by (20);

$$
x(i, j, k)=x(i, j, k)+\sigma^{*} \operatorname{rand}[0,(n F P+n R P)]
$$

d. Substitution: New combination of $R P$ is tested for next match. If tested vector is presents a successful solution then exist vector is accepted to team by substitution operator as follows;

$$
\begin{aligned}
& R P_{\text {new }}(i, j)=\alpha^{*} R P(i, j)+(1-\alpha) * R P(i, k) \\
& R P_{\text {new }}(i, k)=\alpha * R P(i, k)+(1-\alpha) * R P(i, j)
\end{aligned}
$$

3. League update: Teams are rearranged at the end of the seasons. Powerful player are send to best teams and weak players are sent to worst teams.

\subsection{Artificial Bee Colony}

ABC algorithm was proposed for solving optimization problems (Karaboga \& Basturk, 2007). In a colony, bees are divided in three groups such as employed bees, onlookers and scouts. Each of employed bees locate in a food source within the principles of neighborhood. Employed bees release the quality of food source in the hive and onlooker beers decide the food source to collect the nectar within neighborhood. Other other side, scout bees are dispersed to discover more quality food sources. Employed bees turn into scout bee when the its' food sorces is finished. Each food source indicates vector which contains D control variables and food sources donates candidate solutions. Steps of ABC can be defined as follows;

1. Initialization: Food sources are randomly generated within boundaries.

$$
x_{i j}=x_{j}^{\min }+\operatorname{rand}(0,1) *\left(x_{j}^{\max }-x_{j}^{\min }\right)
$$

2. Producing new food sources: New food sources $v_{i}$ is decided with neighborhood principle

$$
v_{i j}=x_{i j}+\phi_{i j} *\left(x_{i j}-x_{k j}\right)
$$

3. Defining the quality of new source: Greedy selction is applied for decide ne sourced. If the new source is more quality, food source is updated. Otherwise old food source is continued to be kept. 


$$
\text { fitness }_{i}=\left\{\begin{array}{ll}
1 /\left(1+f_{i}\right) & f_{i} \geq 0 \\
1+a b s\left(f_{i}\right) & f_{i}<0
\end{array}\right\}
$$

Determining the new source: More quality source have more probability to be selected.

$$
p_{i}=\frac{\text { fitness }_{i}}{\sum_{i=1}^{S N} \text { fitness }_{i}}
$$

\subsection{Particle Swarm Optimization}

PSO is developed by inspiration from food searching of birds ( Kennedy, 1995). Particles represents solution vectors in the space is similar to searching solution for a problem. The velocity and position of the particle are used for food searching. In D-dimensional search space position and velocity vector of the $i$ th particle is defined as $x_{i}=\left(x_{i 1}, x_{i 2}, \ldots, x_{i D}\right)$ and $v_{i}=\left(v_{i 1}, v_{i 2}, \ldots, v_{i D}\right)$, respectively. PSO is initialized randomly and best solutions are searched by updating position and velocity. Previous and best solutions are represented as $p_{\text {best }, i}=\left(p_{i 1}, p_{i 2}, \ldots, p_{i D}\right)$ and $g_{\text {best }, i}$ respectively.

Velocity of the $i$ th particle is updated as follows;

$$
v_{i}^{(t+1)}=w v_{i}^{(t+1)}+c_{1} r_{1}\left(p_{\text {best }, i}-x_{i}^{(t)}\right)+c_{1} r_{1}\left(g_{\text {best }, i}-x_{i}^{(t)}\right)
$$

Position of the $i$ th particle is updated as follow;

$$
x_{i}^{(t+1)}=x_{i}^{(t)}+v_{i}^{(t+1)}
$$

$t$ is the number of current generation, $r_{1}, r_{2}$ are uniform random value in the range[0,1], $w$ is inertia weight factor, $c_{1}, c_{2}$ are acceleration constant of $p_{\text {best }, i}$ and $g_{\text {best }, i}$

\section{Results and Discussion}

Two different nonlinear power systems are separately considered as case studies to prove the superiority and efficiency of SLC algorithm for solution of LFC. Test system models including transfer functions and coding process of algorithms are performed in Matlab/Simulink software. ITAE of the system is minimized using SLC algorithm to determine best values of controller parameters. For implementation of SLC algorithm, nTeams $=3 n F P=5$, $n R P=5$ are selected. Simulations are carried out for as 50,100 and 200 iteration numbers. Note that, increasing iteration number and population size may improve the results but the computation time will be significantly increased. Since, SLC algorithms reach the optimum or near optimum values at the end of 50 iterations, frequency and tie line deviations are illustrated for 50 iteration number. Simulations were run for 50 times and best results are provided. The settling times of frequency are evaluated within $2 \%$ tolerance band. Firstly, two area nonlinear thermal power plants with \pm 0.05 value of GRC is considered as test system and algorithm is evaluated in comparison with some presented optimization algorithms such as BFOA (Ali \& Abd-Elazim, 2013) and hFAPS(Sahu et al., 2015a). Later, the examinations are made on three nonlinear unequal area power system that considers significant physical constraints, which highly increase the instability of the power system in order to examine the proposed SLC on a realistic test system. Besides, PSO and ABC are also simulated for three nonlinear unequal area power system and obtained results are compared to each other.

\section{Test System-1: Two area power system with GRC}

In the case, the simulation is employed with nonlinear system which considers GRC of turbine. The system is demonstrated in Figure A1 in Appendix. Steam and hydro turbines power generation can vary within an indicated maximum generation limit and maximum rate of valve speed is controlled by the regulator. The reheat unit generation rate generally varies between of $3-10 \%$ p.u. MW/min. GRC defines a limitation for ability of compensating large transient disturbances that causes the controller to damage. Hence, linear problem solution technique may be unsuitable for LFC of a nonlinear power system. In case of GRC is considered in a system, a linear system transforms into nonlinear system. GRC values of \pm 0.05 are considered and dynamic response of the given system is examined with $5 \%$ SLP in area-1. 
Optimum parameters and results of performance indices are given in Table 1 . SLC presents $0.2397,0.2390$ and 0.2390 after 50, 100 and 200 iteration, respectively. It should be noted that, differences of the results after $50^{\text {th }}$ and $200^{\text {th }}$ iterations are very small. However, simulation time is extremely increased for 200 iterations. Simulation times are 2929, 5995 and $9673 \mathrm{sec}$. for 50, 100 and 200 iteration numbers. Therefore, comparison will be evaluated for 50 iteration results of SLC. ITAE values of $0.4788,0.2782$ are obtained using BFOA, hFA-PS, respectively. It is clearly observed that minimum ITAE value is attained with SLC along the compared algorithms even after 50 iteration. The ITAE value with proposed SLC is improved by $49.93 \%$ and $13.83 \%$ regarding BFOA and hFA-PS, respectively.

Table 1. Controller parameters and ITAE values of test system-1.

\begin{tabular}{|c|c|c|c|c|}
\hline & \multirow[b]{2}{*}{$\begin{array}{l}\text { BFOA } \\
\text { (Ali \& Abd- } \\
\text { Elazim, 2013) }\end{array}$} & \multirow[b]{2}{*}{$\begin{array}{l}\text { hFA-PS } \\
\text { (Sahu et al., } \\
\text { 2015a) }\end{array}$} & \multicolumn{2}{|c|}{ SLC } \\
\hline & & & $\begin{array}{l}\text { Iteration } \\
\text { number }=50\end{array}$ & $\begin{array}{l}\text { Iteration } \\
\text { number }=100 \\
\& 200\end{array}$ \\
\hline Kp1 & 0.1317 & 0.3834 & 1.5579 & 1.9308 \\
\hline Ki1 & 0.4873 & 0.6127 & 0.6596 & 0.6629 \\
\hline Kd1 & 0.2506 & 0.4021 & 1.0757 & 1.3545 \\
\hline Kp2 & 0.1317 & 0.3834 & -0.1684 & -0.6909 \\
\hline $\mathrm{Ki2}$ & 0.4873 & 0.6127 & 0.1047 & $-1.6646^{*} 10^{-5}$ \\
\hline Kd2 & 0.2506 & 0.4021 & 1.4573 & 1.11427 \\
\hline ITAE & 0.4788 & 0.2782 & 0.2397 & 0.2390 \\
\hline
\end{tabular}

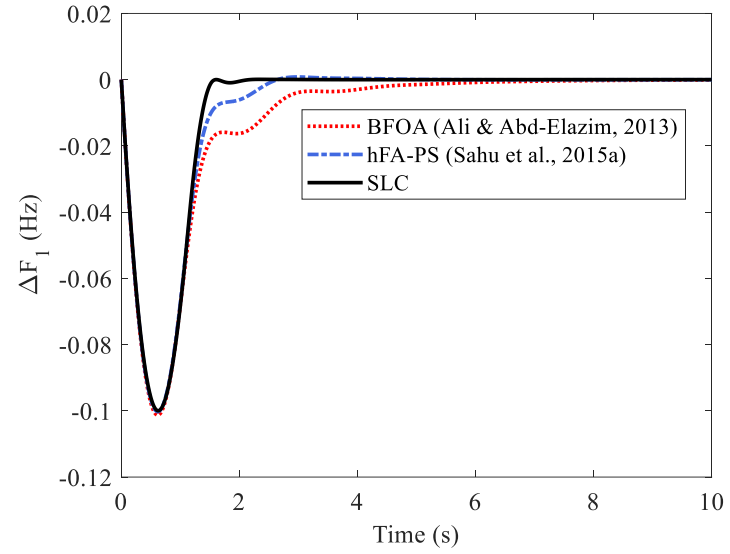

Figure 3. Frequency deviation in area-1 of test system-1

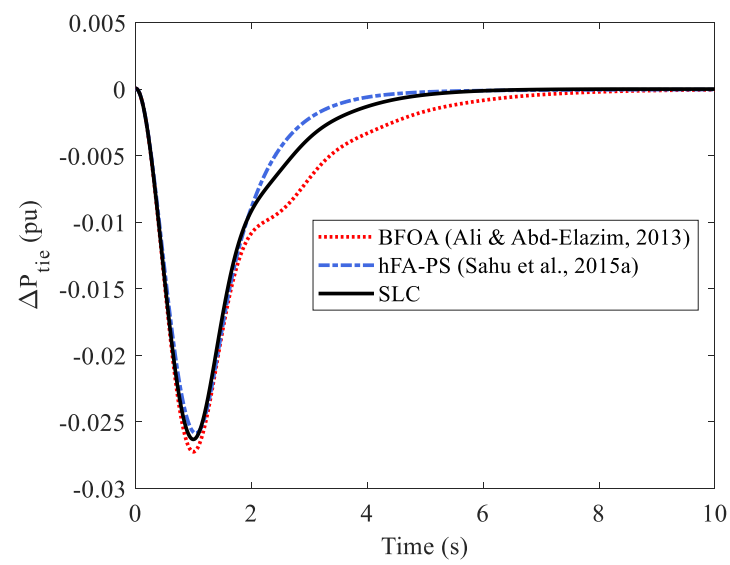

Figure 5. Tie line power change of test system-1

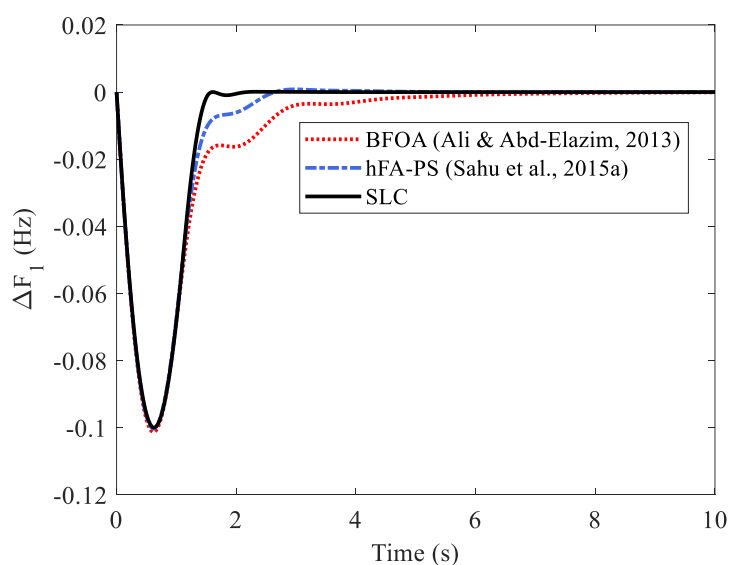

Figure 4. Frequency deviation in area-2 of test system-1

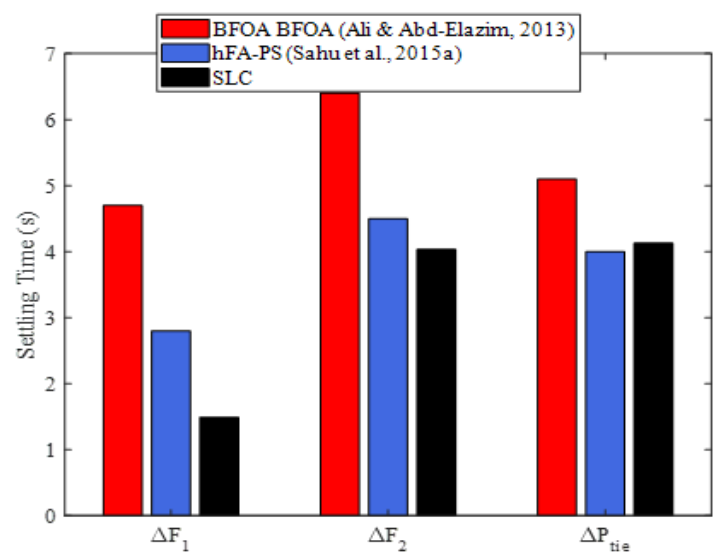

Figure 6. Settling time comparison for test system-1

The dynamic performance of test system is optimized considering PID controller and ITAE performance indices using SLC for given load perturbation. System results for 50 iterations are shown in Figure 3 - Figure 5. Also, comparative illustration of settling times of frequency deviations and tie line power changes are provided in Figure 
6. Settling times of $\Delta f_{1}$ are 4.70, 2.80 and 1.50 sec. using BFOA, hF-PS, and SLC, respectively. Similarly, settling times of $\Delta f_{2}$ are 6.40, 4.50 and 4.03 sec. using BFOA, hFA-PS and SLC, respectively. Besides, settling times of $\Delta P_{\text {tie }}$ are 5.10, 4.00 and $4.13 \mathrm{sec}$. for BFOA, hFA-PS and SLC, respectively. Settling times of $\Delta f_{1}$ is improved by $68.08 \%$, $46.42 \%$ respecting BFOA, hFA-PS, respectively. In addition, settling times of $\Delta f_{2}$ is improved by $37.03 \%, 10.44 \%$ using BFOA, hFA-PS, respectively. Settling times of $\Delta P_{\text {tie }}$ for SLC is $21.56 \%$ lower regarding BFOA and it is $3.25 \%$ higher than hFA-PS. Very limited overshoots occur for each area and the tie line. Best performance for undershoots are obtained using SLC. They are $0.1000,0.0625$ and 0.0259 for area-1, area- 2 and tie-line, respectively. Iteration times of BFOA and hFA-PS are non-available in the literature. In summary, minimum values of objective function is obtained while settling time of the frequencies are significantly improved using SLC.

\section{Test System-2: Three-area nonlinear unequal power system}

GDB and TD are significant physical boundaries with GRC that increase the nonlinearity and disrupt the regular operation of power systems. In smart power systems, communication is most important tool in terms of coordinating whole power system. Therefore, time delays of communication signal negatively affects the system output and increase the system instability, as well. GDB is defined as the total values of a continued speed change while no change is observed in valve position. GDB occurs as a result of the backlash in the linkage between servo piston and the camshaft. In case of existing GDB even for a small load disturbances, the system becomes highly nonlinear and fluctationary.

To obtain accurate simulation of LFC problem and illustrate effectiveness of the SLC, the study is more extended to complicate, highly nonlinear and realistic power system that is illustrated in Figure A2 in Appendix. Test system2 is a three area nonlinear unequal system model considers the important constraints such GRC, GDB, TD which affect the overall performance of power system. The dynamic performance of test system-2 is analyzed with $1 \%$ step load perturbation (SLP) in area-1 on highly nonlinear and complex test systems. For the analysis, GDB of governor and GRC are considered as $0.06 \%$ and 3\% for thermal system. Additionally, Time delay is assumed 50 ms. SLC, ABC and PSO are repetitively run for 50, 100 and 200 iterations and best results are provided. PSO parameters are as follows; $c_{1}=1.2, c_{2}=1.2, r_{1}=0.5$, epoch number $=30$, ABC parameters are selected as; limit $=200$, Colony size $=30$ and SLC parameters are as given; $n$ teams $=3, n F P=5, n R P=5$. Searching space of SLC is calculated with $(n t e a m s \times(n F P+n R P))$. Searching space of each algorithms are decided as 30 for fair comparison.

Table 2. Controller parameters and ITAE values of test system-2.

\begin{tabular}{|c|c|c|c|c|c|c|c|c|c|}
\hline & \multicolumn{3}{|c|}{ iteration number $=50$} & \multicolumn{3}{|c|}{ iteration number $=100$} & \multicolumn{3}{|c|}{ iteration number $=200$} \\
\hline & PSO & ABC & SLC & PSO & ABC & SLC & PSO & ABC & SLC \\
\hline Kp1 & -0.4096 & 0.2761 & 0.3671 & 0.5001 & 0.5001 & 0.3671 & 0.3684 & 0.3680 & 0.3657 \\
\hline Ki1 & -1.4999 & -1.5000 & -1.5000 & -1.5000 & -1.5000 & -1.5000 & -1.5000 & -1.5000 & -1.5000 \\
\hline Kd1 & 0.1633 & 0.0570 & 0.1632 & 0.1435 & 0.4153 & 0.1645 & 0.1589 & 0.1700 & 0.1645 \\
\hline Kp2 & -0.8292 & -1.5000 & -1.5000 & -1.3839 & -1.3839 & -1.4997 & -1.4985 & -1.5000 & -1.4997 \\
\hline Ki2 & -1.2496 & 0.8538 & -1.5000 & -1.3883 & -1.3883 & -1.5000 & -1.4834 & -1.5000 & -1.5000 \\
\hline Kd2 & -1.4983 & -1.5000 & -1.5000 & -1.5000 & -1.5000 & -1.4998 & -14965 & -1.5000 & -1.4998 \\
\hline Kp3 & -14506 & -1.5000 & -1.5000 & -1.5000 & -1.5000 & -1.5000 & -1.4961 & -1.5000 & -1.5000 \\
\hline $\mathrm{Ki3}$ & -1.4807 & -1.5000 & -1.4995 & -1.5000 & -1.5000 & -1.4998 & -1.5000 & -1.4918 & -1.4998 \\
\hline Kd3 & -1.4631 & -1.2662 & -1.5000 & -1.5000 & -1.5000 & -1.5000 & -14971 & -1.5000 & -1.5000 \\
\hline ITAE & 0.1747 & 0.1796 & 0.1717 & 0.1720 & 0.1765 & 0.1717 & 0.1718 & 0.1718 & 0.1717 \\
\hline
\end{tabular}

ITAE results and optimum values of controller parameters for PSO, ABC and SLC are given in Table 2. ITAE values are 0.1747 and 0.1796 and 0.1717 for $50^{\text {th }}$ iteration number with PSO, ABC and SLC, respectively. The ITAE values of SLC algorithms are 0.1717 for 100 and 200 iteration, as well. PSO improved the results with increased iteration number. They are 0.1720 and 0.1718 for 100 and 200 iteration number, respectively. Similarly, ABC provides 0.1765 and 0.1718 as ITAE values for 100 and 200 iterations, respectively. As the result show that SLC reach the best result with 0.1717 at the end of the 50 iteration. However, best results of PSO and ABC are obtained as 0.1718 at the end of 200 iteration. Although PSO and ABC improved the results with increased iteration number, SLC presents better ITAE values than both ABC and PSO even for $50^{\text {th }}$ iteration. It is obvious that, SLC algorithm 
outperform as minimum ITAE value in comparison to PSO and ABC.

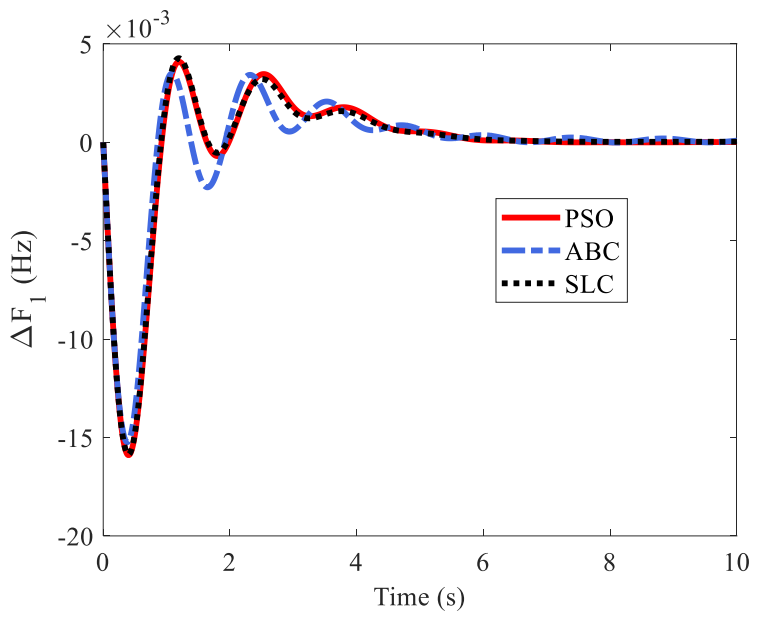

Figure 7. Frequency deviation in area-1 of test system-2

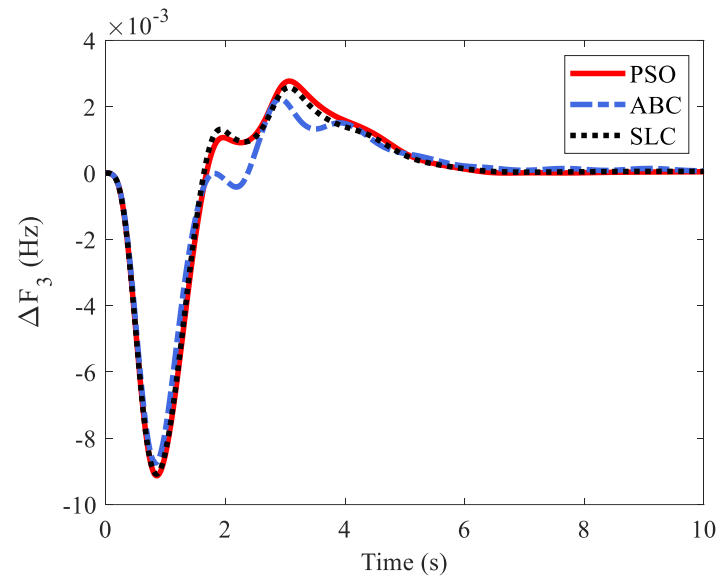

Figure 9. Frequency deviation in area-3 of test system-2

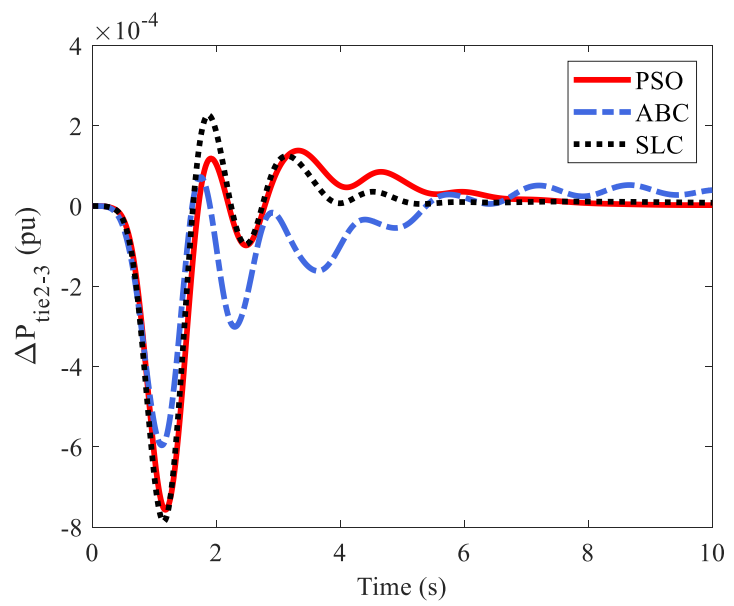

Figure 11. Tie line 2-3 power change of test system-2

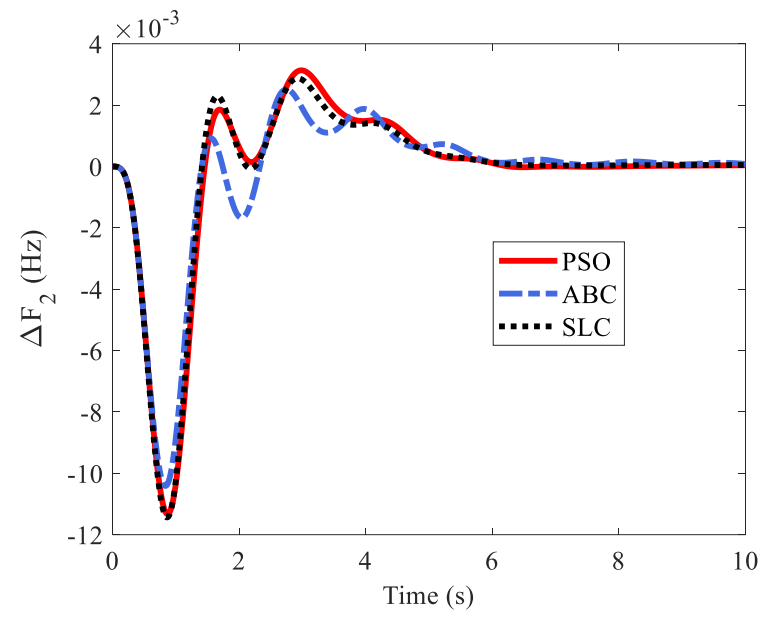

Figure 8. Frequency deviation in area-2 of test system-2

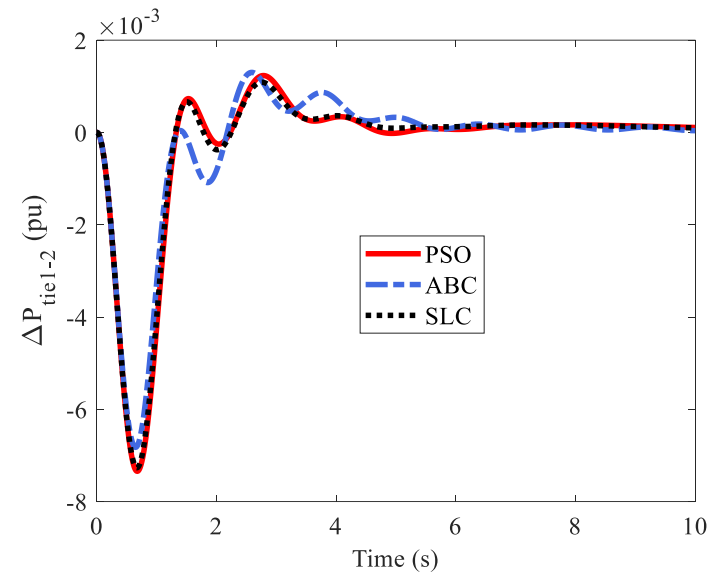

Figure 10. Tie line 1-2 power change of test system-2

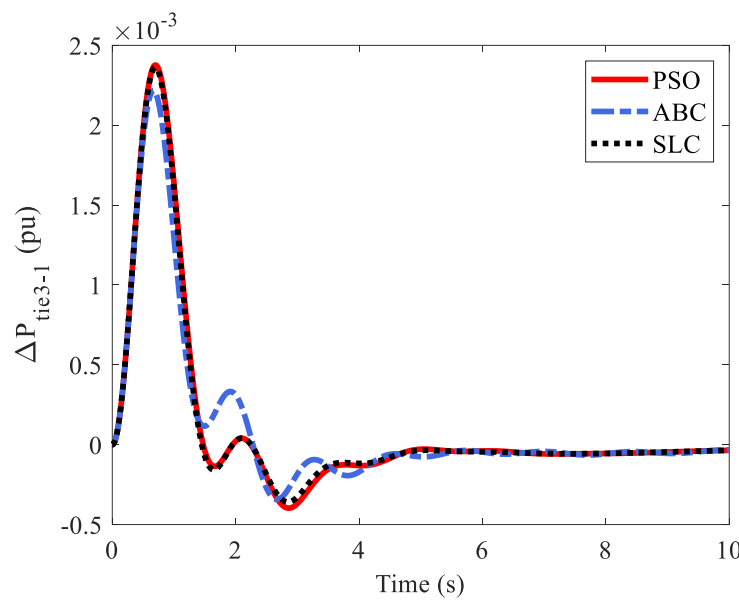

Figure 12. Tie line 3-1 power change of test system-2

Transient response of test system regarding SLP are demonstrated in Figure 7 - Figure 12 and comparative settling time results are illustrated in Figure 13. Setting time of frequency and tie-line power variations are noted as follows; settling times of $\Delta f_{1}$ are 5.53, 6.17 and 5.47 sec. for PSO, ABC and SLC, respectively. Similarly, settling times of $\Delta f_{2}$ are 5.75, 6.87 and $5.68 \mathrm{sec}$. using PSO, ABC and SLC, respectively. Settling times of $\Delta f_{3}$ are 5.79, 6.31 and 5.79 sec. using PSO, ABC and SLC, respectively. Settling times of $\Delta P_{t i e l-2}$ are 8.80, 8.02 and 8.45 sec. for PSO, $\mathrm{ABC}$ and SLC, respectively. Similarly, settling times for $\Delta P_{\text {tie-2-3 }}$ are 7.25, 14.57 and 4.94 sec. using PSO, ABC and SLC, respectively. Settling times for $\Delta P_{\text {tiel-3 }}$ are 8.83, 9.50 and $8.84 \mathrm{sec}$. for PSO, ABC and SLC, respectively. SLC algorithm 
presents the minimum settling times along the considered algorithms for each areas and tie lines except for $\Delta P_{\text {tiel-2 }}$ . SLC improved the settling times regarding PSO and ABC up to 66.09\%. Only settling time with ABC is 5.08\% less than SLC in $\Delta P_{\text {tiel-2 }}$. On the other hand, ABC has lesser overshoots rates for most of areas and tie lines. SLC only has less overshoot rate for $\Delta P_{\text {tiel-2 }}$. They are 0.001233 p.u., 0.001302 p.u. and 0.001089 p.u. using PSO, ABC and SLC, respectively. Also, $\mathrm{ABC}$ provides minimum undershoot rates for each areas and tie lines. It is clearly noted from the results that significant improvement of settling time of frequency deviation and power change in most of area is provided. Simulation times of PSO, ABC and SLC are 1187.4, 1368.1 and $2261 \mathrm{sec}$. SLC provides minimum settling times for frequency of each areas. Moreover, SLC has minimum settling time for $\Delta P_{\text {tiel-2 }}$ and $\Delta P_{\text {tie2-3 } 3}$. Although SLC has the minimum result at $50^{\text {th }}$ iteration, PSO and ABC continued to improve the results. Even after 200 iterations, PSO and ABC could not reach the value that obtained by SLC at the end of 50 iterations. On the other side, PSO has better performance than $\mathrm{ABC}$.

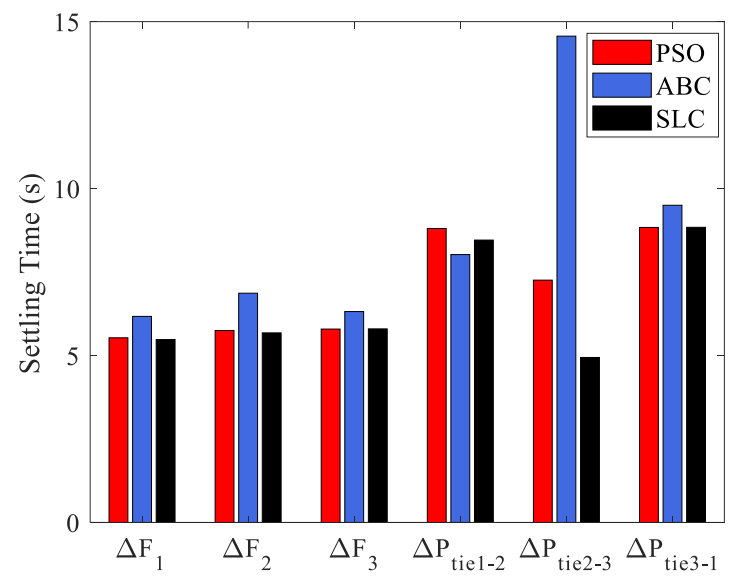

Figure 13. Settling time comparison of test system-2.

In both cases, multi source multi area with nonlinearities are considered for simulations and PID controller parameters are decided using SLC algorithm. Results are compared with literature results in Case-I while PSO and ABC algorithms are also employed for three area unequal test system in Case-II. According to simulation results SLC algorithm provides best results with minimum iteration number. SLC stands out among other algorithms due to its simultaneous global and local searching capability.

\section{Conclusion}

Frequency control has vital importance for stable operation of the power systems. If the power systems is combination of the interconnected areas, disturbances of the system extremely affect the all areas. Therefore, controller parameters of the systems should be carefully selected. The paper analysis application of SLC algorithm for the first time to optimize PID controller parameters of LFC problem in nonlinear multi-area interconnected power systems. Performance of the algorithm is investigated for 50,100 and 200 iteration numbers for each cases. Initially, nonlinear two area test system with generation rate constraint is carried out. SLC algorithm reached the minimum ITEA value and settling times regarding BFOA and hFA-PS. Then, the study is extended to three area highly nonlinear unequal interconnected power system that includes significant physical constraints such as Governor Dead Band, Time Delay and Generation Rate Constraint nonlinearities. Dynamic responses analyses clearly reveal that minimum ITAE values and better dynamic performances are obtained with proposed SLC in comparison to PSO and ABC. While the best result is reached at the end of $50^{\text {th }}$ iterations with SLC, PSO and ABC were not able to present better results even after $200^{\text {th }}$ iterations. It is observed that SLC provides satisfactory performance in different interconnected power systems in presence of nonlinearities. However, SLC has slower simulation times. To sum it up, SLC algorithm has local search capability as much as global search capability, it is regarded as an suitable method for load frequency control problems in power system. As future work, different controller structure can be adopted to multi area power systems considering transfer functions of electric vehicle load and renewable generators.

\section{Conflict of Interest}

No conflict of interest was declared by the author. 


\section{Appendix}

Test System-1(Ali \& Abd-Elazim, 2013):

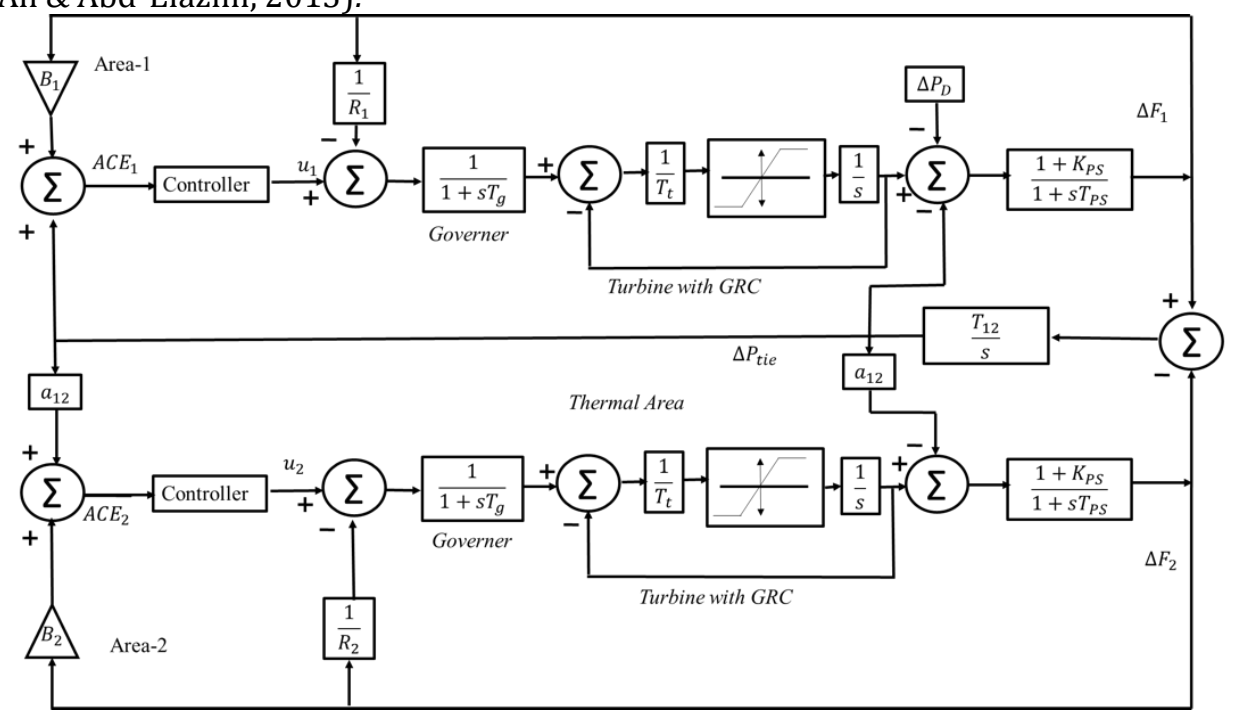

Figure A1. Two area interconnected power system with GRC

Test System-2(Golpîra et al., 2011):

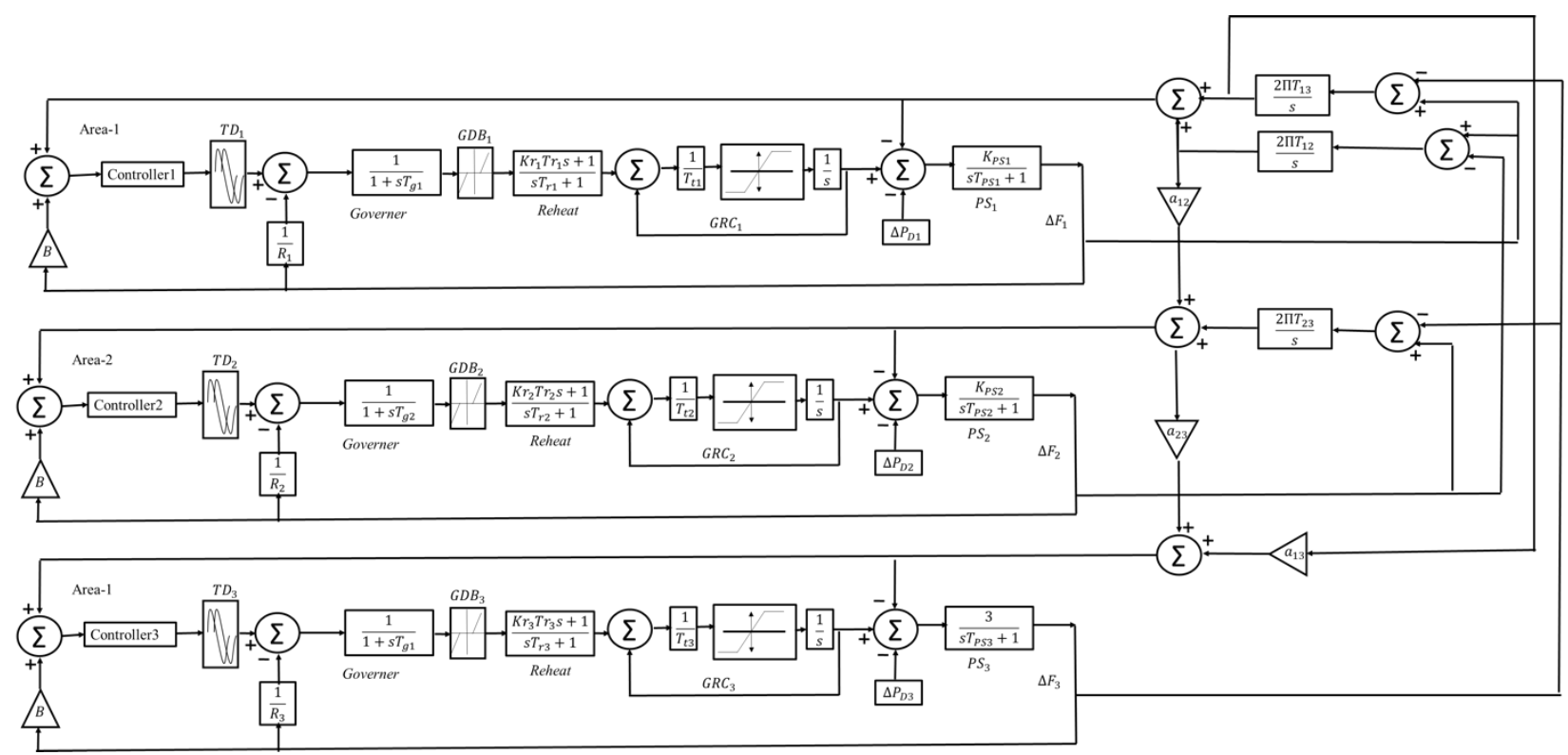

Figure A2. Three unequal area interconnected power system with RH, TD, GRC and GDB

\section{References}

Ali, E. S., \& Abd-Elazim, S. M. (2013). BFOA based design of PID controller for two area Load Frequency Control with nonlinearities. International Journal of Electrical Power and Energy Systems, 51, 224-231. https://doi.org/10.1016/j.ijepes.2013.02.030

Borase, R. P., Maghade, D. K., Sondkar, S. Y., \& Pawar, S. N. (2020). A review of PID control, tuning methods and applications. International Journal of Dynamics and Control, June. https://doi.org/10.1007/s40435-020-00665-4

Dogan, A. (2019). Load Frequency Control of Two Area and Multi Source Power System Using Grey Wolf Optimization Algorithm. ELECO 2019 - 11th International Conference on Electrical and Electronics Engineering, 81-84. https://doi.org/10.23919/ELEC047770.2019.8990643

Dogan, A. (2021). Optimum sitting and sizing of WTs, PVs, ESSs and EVCSs using hybrid soccer league competition-pattern search algorithm. Engineering Science and Technology, an International Journal, In press. https://doi.org/10.1016/j.jestch.2020.12.007

Ebrahimi, S., \& Tabatabaei, S. (2020). Using Clustering via Soccer League Competition Algorithm for Optimizing Power Consumption in WSNs (Wireless Sensor Networks). Wireless Personal Communications, 113(4), $2387-2402$. https://doi.org/10.1007/s11277-020-07332-z 
Fujita, H., Ali, M., Selamat, A., Sasaki, J., \& Goebel, R. (2016). Trends in Applied Knowledge-Based Systems. 884-891.

Golpîra, H., Bevrani, H., \& Golpîra, H. (2011). Application of GA optimization for automatic generation control design in an interconnected power system. Energy Conversion and Management, 52(5), 2247-2255. https://doi.org/10.1016/j.enconman.2011.01.010

Guha, D., Roy, P. K., \& Banerjee, S. (2016). Load frequency control of interconnected power system using grey Wolf optimization. Swarm and Evolutionary Computation, 27, 97-115. https://doi.org/10.1016/j.swevo.2015.10.004

Guha, D., Roy, P. K., \& Banerjee, S. (2018). Application of backtracking search algorithm in load frequency control of multi-area interconnected power system. Ain Shams Engineering Journal, 9(2), 257-276. https://doi.org/10.1016/j.asej.2016.01.004

Guha, D., Roy, P. K., \& Banerjee, S. (2020). Whale optimization algorithm applied to load frequency control of a mixed power system considering nonlinearities and PLL dynamics. Energy Systems, 11(3), 699-728. https://doi.org/10.1007/s12667019-00326-2

Hasanien, H. M. (2018). Whale optimisation algorithm for automatic generation control of interconnected modern power systems including renewable energy sources. IET Generation, Transmission and Distribution, 12(3), 607-614. https://doi.org/10.1049/iet-gtd.2017.1005

Hasanien, H. M., \& El-Fergany, A. A. (2019). Salp swarm algorithm-based optimal load frequency control of hybrid renewable power systems with communication delay and excitation cross-coupling effect. Electric Power Systems Research, 176,110. https://doi.org/10.1016/j.epsr.2019.105938

Karaboga, D., \& Basturk, B. (2007). A powerful and efficient algorithm for numerical function optimization: Artificial bee colony (ABC) algorithm. Journal of Global Optimization, 39(3), 459-471. https://doi.org/10.1007/s10898-007-9149-x

Kennedy, J., Eberhart, R. (1995). Particle swarm optimization, in Proc. IEEE Int. Conf Neural Networks, 1942-1948. https://doi.org/10.1109/ICNN.1995.488968

Mahendran, M. V., \& Vijayan, V. (2021). Model-predictive control-based hybrid optimized load frequency control of multi-area power systems. IET Generation, Transmission and Distribution, October 2020, 1-17. https://doi.org/10.1049/gtd2.12119

Moosavian, N. (2015). Soccer league competition algorithm for solving knapsack problems. Swarm and Evolutionary Computation, 20, 14-22. https://doi.org/10.1016/j.swevo.2014.10.002

Moosavian, N., \& Kasaee Roodsari, B. (2014). Soccer league competition algorithm: A novel meta-heuristic algorithm for optimal design of water distribution networks. Swarm and Evolutionary Computation, 17, 14-24. https://doi.org/10.1016/j.swevo.2014.02.002

Moosavian, N., \& Roodsari, B. K. (2014). Soccer League Competition Algorithm, a New Method for Solving Systems of Nonlinear Equations. International Journal of Intelligence Science, 04(01), 7-16. https://doi.org/10.4236/ijis.2014.41002

Qiao, Y., Dao, T. K., Pan, J. S., Chu, S. C., \& Nguyen, T. T. (2020). Diversity teams in soccer league competition algorithm for wireless sensor network deployment problem. Symmetry, 12(3). https://doi.org/10.3390/sym12030445

Sahu, R. K., Panda, S., \& Padhan, S. (2015a). A hybrid firefly algorithm and pattern search technique for automatic generation control of multi area power systems. International Journal of Electrical Power and Energy Systems, 64, 9-23. https://doi.org/10.1016/j.ijepes.2014.07.013

Sahu, R. K., Panda, S., \& Padhan, S. (2015b). A novel hybrid gravitational search and pattern search algorithm for load frequency control of nonlinear power system. Applied Soft Computing Journal, 29, 310-327. https://doi.org/10.1016/j.asoc.2015.01.020

Vedik, B., Kumar, R., Deshmukh, R., Verma, S., \& Shiva, C. K. (2021). Renewable Energy-Based Load Frequency Stabilization of Interconnected Power Systems Using Quasi-Oppositional Dragonfly Algorithm. Journal of Control, Automation and Electrical Systems, 32(1), 227-243. https://doi.org/10.1007/s40313-020-00643-3

Wang, X., Wang, Y., \& Liu, Y. (2020). Dynamic load frequency control for high-penetration wind power considering wind turbine fatigue load. International Journal of Electrical Power and Energy Systems, 117(November 2019), 105696. https://doi.org/10.1016/j.ijepes.2019.105696 